\title{
SALÃO PARCEIRO NA PRÁTICA: SUBMISSÃO OU AUTONOMIA?
}

\author{
"SALÃO PARCEIRO” EN LA PRÁCTICA: \\ ¿SUMISIÓN O AUTONOMÍA?
BEAUTY SALON PARTNER IN PRACTICE: SUBMISSION OR AUTONOMY?

\author{
Mariana Machado Souza ${ }^{1}$ e Livia de Oliveira Borges ${ }^{1}$ \\ ${ }^{1}$ Universidade Federal de Minas Gerais, Belo Horizonte/MG, Brasil
}

RESUMO: A Lei do Salão Parceiro em 2016 foi aprovada sob o discurso da flexibilização e formalização do trabalho autônomo; entretanto, o processo de pejotização dos trabalhadores tem sido um de seus efeitos e estudado sob o olhar da precarização do trabalho. A presente pesquisa objetivou caracterizar a percepção de manicures e cabeleireiras(os) acerca de suas experiências de trabalho e confrontá-la com os argumentos presentes na proposição da lei. Para isso, realizamos entrevistas semiestruturadas com 11 cabeleireiras(os) e manicures e aplicamos análise hermenêuticadialética. Os resultados indicaram três unidades de sentido: Caracterização mercadológica e ocupacional; Tradições trabalhistas no setor de beleza; e Realidade após a Lei do Salão Parceiro. Elas apontaram a ausência de uma autonomia real na mudança e no exercício da atividade como parceiro do salão de beleza e a desinformação acerca da figura jurídica do microempreendedor individual.

PALAVRAS-CHAVE: Salão de beleza; Microempreendedor individual; Análise hermenêutica-dialética.

RESUMEN: La Lei do Salão Parceiro, de 2016, fue aprobada bajo el discurso de la flexibilización y formalización del trabajo autónomo; sin embargo, el proceso de pejotização (prestador de servicios legal) ha sido uno de sus efectos y, estudiado bajo la mirada de la precarización del trabajo. Esta investigación tuvo como objetivo caracterizar la percepción de manicuras y peluqueras(os) sobre sus experiencias laborales y confrontarla con los argumentos presentes en la proposición de la ley. Para esto, realizamos entrevistas semiestructuradas con 11 peluqueras(os) y manicuras y aplicamos el análisis hermenéutico-dialéctico. Los resultados indicaron tres unidades de sentido: Caracterización mercadológica y ocupacional; Tradiciones laborales en el sector de belleza; y Realidad posterior a la Lei do Salão Parceiro. Ellas señalaron la ausencia de una autonomía real en el cambio y en el ejercicio de la actividad como "colaborador" del salón de belleza y desinformación sobre la figura legal del microemprendedor individual.

PALABRAS CLAVE: Salón de belleza; Microemprendedor individual; Análisis hermenéutico-dialéctico.

ABSTRACT: The Lei do Salão Parceiro (Salon Partner Law) was approved in 2016 under speeches of flexibilization and formalization of autonomous work. However, the pejotização of workers has been one of its effects and it has been studied as work precariousness. This research aimed to characterize the perception of manicurists and hairdressers on their work experiences, and to confront it with the arguments present in the law proposal. For this, we conducted semistructured interviews with 11 hairdressers and manicurists, and applied hermeneutic-dialectical analysis. The results indicated three meaning units: Marketing and occupational characterization; Labor traditions in the beauty sector; and Reality after the Lei do Salão Parceiro. They pointed to the absence of a real autonomy in the transition and in the work practice as beauty salon partner, and to the misinformation about the legal figure of the individual microentrepreneur. KEYWORDS: Beauty salon; Individual microentrepreneur; Hermeneutic-dialectical analysis. 


\section{Introdução}

Não era novidade que os salões de beleza no Brasil praticavam diferentes tipos de regimes de contratação simultaneamente, sendo possível encontrar trabalhadores empregados e informais em uma mesma empresa (Venâncio, Dutra, Fiates, \& Feuerschutte, 2015). A aprovação da Lei n⿳0 13.352/2016, a Lei do Salão Parceiro, visou à formalização do contingente de profissionais considerados autônomos, os quais passaram a ser parceiros do salão de beleza e registrados, em geral, como microempreendedores individuais (MEI).

Entretanto, a aprovação da lei ocorreu dentre discussões acerca da validade desse regime de parceria, o qual tem sido considerado por alguns autores (Fernandes, 2018; Santos, 2017) um meio para fraudar a relação de emprego a partir do estabelecimento de uma relação de natureza civil, entre duas empresas. Em outras palavras, a mesma lei que permitiu a formalização dos trabalhadores como profissionais parceiros, também abriu espaço para o processo de pejotização, fenômeno que consiste no tratamento do trabalhador como pessoa jurídica (PJ) ou empresa individual para encobrir uma relação de emprego (Barbosa \& Orbem, 2015; Pereira, 2013), e que tem sido assim designado por alguns autores (Alves, 2013; Antunes, 2018; Pereira, 2013) sob a perspectiva de precarização do trabalho. O neologismo pejotização designa, portanto, esse processo do trabalhador individual passar a ser tratado como PJ, ou seja, pessoa jurídica.

Dessa maneira, questionamos como os próprios trabalhadores do setor de beleza vivenciam a mudança no marco legal, se eles têm clareza a respeito das vantagens e desvantagens, e dos direitos e deveres que passaram a existir, foram extintos e/ou se modificaram, e se o que é apresentado na proposição de lei faz sentido no dia a dia dos profissionais. Por isso, o objetivo da presente pesquisa foi caracterizar a percepção de manicures e cabeleireiras(os) acerca de suas experiências de trabalho e confrontá-la com os argumentos presentes na proposição da Lei do Salão Parceiro.

\section{Setor de serviços e pejotização}

Desde o início dos anos 2000 e com mais intensidade a partir de 2010, vivemos alterações disruptivas nas estruturas econômicas e sociais causadas por tecnologias de domínios físico, biológico e digital. A integração entre esses domínios, no que tem sido denominado quarta revolução industrial, promove mudanças profundas e sistêmicas, em uma velocidade maior, e afeta o futuro do trabalho, das profissões, das relações e do acesso a oportunidades e renda. Entretanto, a revolução e suas mudanças não ocorrem de maneira vantajosa e homogênea em todos os países, setores econômicos e classes sociais (Bonciu, 2017; Schwab, 2016).

Com lugar de destaque nesse contexto, o setor de serviços vive uma intensa expansão e participa cada vez mais das cadeias produtivas de valor (Antunes, 2018; Bonciu, 2017). Nele, a produção é marcada pela intangibilidade, ocorre no mesmo tempo e espaço que o consumo, e o consumidor está inserido no ambiente de trabalho e participa da produção (Meirelles, 2006). Com as mudanças tecnológicas e sociais que a quarta revolução industrial vem promovendo, novas tendências de práticas organizacionais no setor de serviços criam uma morfologia diferente do trabalho, por meio da qual o trabalhador é exigido sob novos tipos de relações, muitas vezes precárias e não padronizadas (Antunes, 2018; Hewison, 2016). 
Nesse contexto, a sociedade se depara com o desafio de negociar coletivamente e aplicar, criar e adequar leis que regulamentem as novas formas de trabalho. A pretexto dessa modernização, uma das teses que ganhou força foi a da necessidade de flexibilização trabalhista, levando à coexistência de diferentes práticas que ampliam as possibilidades de manejo da força de trabalho pelas empresas. Algumas formas mais comuns são trabalho temporário, terceirização, uberização, criação de cooperativas e prestação pessoal de serviços por meio de pessoas jurídicas (Arnold \& Bongiovi, 2013; Carvalho, 2010; Galvão \& Teixeira, 2017; Standing, 2013/2017), como é o caso do praticado nos salões de beleza do país.

Historicamente a "Lei do Bem", Lei nº 11.196 de 2005, viabilizou a contratação de um trabalhador na condição de pessoa jurídica para execução de trabalho intelectual considerado na lei como trabalho artístico, científico ou cultural (Lei n. 11196/2005). Entretanto, a conduta passou a ser utilizada rapidamente para burlar relações de emprego de diferentes categorias não intelectuais (Barros, 2014; Pereira, 2013). Na prática, as empresas demitem seus funcionários, mas, após o desligamento, estes retomam a prestação de serviços sob a forma de contrato entre duas empresas, tendo o trabalhador se tornado uma pessoa jurídica (PJ) (Carvalho, 2010).

Isso significa que, de um lado, a legislação trabalhista deixa de reger tais relações sociais, eximindo o empregador dos custos de carga tributária, de previdência social, de imposto de renda, bem como do recolhimento do Fundo de Garantia por Tempo de Serviço (FGTS) e pagamentos de 13ํㅗ salário, férias etc. (Antunes, 2018; Barbosa \& Orbem, 2015; Carvalho, 2010; Oliveira, 2013; Pereira, 2013). De outro lado, o trabalhador assume os riscos de exercer a atividade no lugar da empresa e do governo e, como consequência, passa a vivenciar incerteza, vulnerabilidade, instabilidade e insegurança da situação de trabalho, fenômeno já conhecido como precarização (Standing, 2013/2017; Hewison, 2016; Kalleberg \& Hewinson, 2013).

Poucos estudos aprofundaram acerca da ocorrência e dos efeitos da pejotização. Algumas categorias que vivenciam o fenômeno são os profissionais de saúde (Carvalho, 2010), jornalistas e publicitários (Silva, 2014) e profissionais de tecnologia (Bridi \& Braunert, 2015). Outras que a Justiça do Trabalho já reconheceu vínculo empregatício são bancários e professores de cursinhos preparatórios para concursos (Pereira, 2013).

Em 2008, a criação da figura jurídica do Microempreendedor Individual (MEI) estabeleceu diretrizes para trabalhadores informais se formalizarem no país. Para se enquadrarem como MEI, eles devem apresentar receita bruta de até $\mathrm{R} \$$ 81.000,00 por ano, exercerem as atividades permitidas pelo programa, não participarem de outros empreendimentos como sócios, titulares ou administradores, e contratarem até 1 empregado que receba um salário mínimo (Lei complementar 128/2008). Em 2017, o Brasil alcançou a marca de 6,6 milhões de MEIs, garantindo a formalização e inclusão previdenciária e social de muitos brasileiros (SEBRAE, 2017). Entretanto, na prática, a nova figura jurídica passou a representar um vetor eficaz para a fraude de direitos daqueles que são empregados, facilitando a ocorrência da pejotização (Krein, Abílio, Freitas, Bolsari \& Cruz, 2017; Pereira, 2013).

Um dos cenários que facilitaram a ocorrência do fenômeno foi o mito do trabalho autônomo (Antunes, 2018; Jesus, 2016). Ele estabeleceu um discurso do “patrão de si mesmo”, prometendo liberdade e status. Entretanto, do ponto de vista das relações de trabalho, tem se expressado no isolamento e desmonte da classe trabalhadora, na responsabilização e 
culpabilização dos sujeitos, bem como na perda de direitos trabalhistas e sociais (Alves, 2013; Antunes, 2018; Arnold \& Bongiovi, 2013; Krein, 2013). Dessa forma, flexibilidade e precariedade apresentam-se indissoluvelmente ligadas na organização social do trabalho (Thébaud-Mony \& Druck, 2007).

\section{Salões de beleza no Brasil e a Lei do Salão Parceiro}

O mercado de beleza brasileiro viveu um crescimento médio significativo nos últimos $10 \operatorname{anos}(4 \%)$, tendo recuado pouco durante o período de retração econômica do país (ABIHPEC, 2018), e incorporou novos produtos e técnicas, acompanhando tendências tecnológicas de outros mercados. Ao mesmo tempo, as relações de trabalho se tornaram cada vez mais precárias e manicures e cabeleireiras(os) estão na ponta desse processo (Fernandes, 2018). O setor é representado por indústrias, as quais produzem cosméticos, perfumes, produtos de cabelo, unha e higiene pessoal dentre outros, bem como por outras empresas, como os salões de beleza, que empregam a força de trabalho que executa o serviço e aplica nos clientes finais boa parte dos produtos produzidos.

Marcadas pela informalidade, as profissões de cabeleireiro, manicure, pedicure, barbeiro, esteticista, depilador e maquiador foram regulamentadas pela Lei $\mathrm{n}^{\mathrm{o}}$ 12.592, de 18 de janeiro de 2012. Esse reconhecimento tardio, entretanto, não trouxe nenhuma consideração a respeito das relações trabalhistas praticadas, mantendo lacunas no regulamento do setor (Fernandes, 2018). Foi em 2016, com a Lei do Salão Parceiro (Lei $\mathrm{n}^{0} 13.352 / 2016$ ), que a lei supracitada foi alterada e as figuras de salão-parceiro e profissional-parceiro foram criadas, bem como regulamentada a relação entre empresa e trabalhador por meio de um contrato escrito de parceria. A lei previu que os profissionais fossem qualificados como pequenos empresários, microempresários ou microempreendedores individuais.

Os argumentos apresentados no projeto de lei (PL 5230/2013), elaborado pelo então deputado Ricardo Izar (Partido Progressista/ São Paulo), focalizaram problemas presentes nos salões de beleza: (a) alta mortalidade dos empreendimentos, sugerindo como causas falta de informação a respeito de direitos e obrigações, bem como gestão ineficiente; e (b) relações de trabalho juridicamente inseguras, contribuindo para a alta informalidade. Como finalidades para a criação do salão-parceiro e do profissional-parceiro, o projeto de lei apresentou a institucionalização dos costumes do setor de beleza, atendendo às suas particularidades, a formalização dos profissionais, a distinção das responsabilidades tributárias e a facilitação de acesso ao crédito e ao microcrédito pelos empreendedores (Izar, 2013).

Para justificar a relação de parceria, o projeto de lei alegou um modelo histórico de usos e costumes nas relações de trabalho no setor, sugerindo a presença de elementos de atividade autônoma. De acordo com ele, os profissionais exerciam seu trabalho com pessoalidade e habitualidade, mas sem subordinação com o salão de beleza. Os horários de atendimento, apesar do processo de marcação estar centralizado na recepção, seriam escolhidos pelo cliente e não pelo salão, e os profissionais poderiam se ausentar sem penalidades por parte da empresa. Compete-nos indagar se tal característica descaracterizou realmente a falta de subordinação ou se tipifica o exercício de uma atividade de serviços. Além disso, de acordo com o projeto, o recebimento via comissão e a compra dos materiais de trabalho pelos próprios trabalhadores não condiziam com a relação empregatícia (Izar, 2013). 
Tal argumento também nos deixou com a indagação se tal descrição descaracterizou também a falta de subordinação empregatícia ou se não denunciou as condições inadequadas de trabalho na situação de emprego?

Outras características levantadas pelo projeto de lei foram a fidelidade do cliente ao profissional, e não ao salão, e os percentuais recebidos, que foram considerados valores altos para serem pagos em uma relação de emprego regida pela Consolidação das Leis do Trabalho (CLT). De acordo com o projeto, os pisos salariais estipulados nas convenções coletivas da categoria servem apenas como referência para as contribuições sindicais e os profissionais não aceitariam tê-los como salário (Izar, 2013). Mas quais seriam as funções de um piso salarial?

O projeto tramitou na Câmara dos Deputados e obteve pareceres favoráveis nas comissões de Trabalho, Administração e Serviço Público, de Desenvolvimento Econômico, Indústria e Comércio, e de Constituição, Justiça e Cidadania. A tramitação e votação no Senado, entretanto, já contou com críticas por parte de representantes dos trabalhadores, a exemplo da Confederação ${ }^{1}$ Nacional dos Trabalhadores em Turismo e Hospitalidade (CONTRATUH) e da Central Única de Trabalhadores (CUT). Os argumentos dessas entidades envolveram aspectos de precarização do trabalho potencializados pelo processo de pejotização (Fernandes, 2018).

Após a aprovação da lei, em 2016, a CONTRATUH, ajuizou uma Ação Direta de Inconstitucionalidade $^{2}$ (ADI n⿳0 5.625) no Supremo Tribunal Federal (STF). Ela alegou que a Lei do Salão Parceiro configura retrocesso social ao violar princípios da dignidade da pessoa humana e dos valores sociais do trabalho, bem como precariza o trabalho no setor de embelezamento ao possibilitar a pejotização, uma vez que burla os direitos fundamentais trabalhistas e rompe com a isonomia nas relações laborais (CONTRATUH, 2016).

Em manifestação presente na tramitação da ADI nº 5.625, que ainda não foi julgada pelo STF, a Procuradoria-Geral da República (PGR) apontou diferentes razões para que a relação entre profissional e salão de beleza seja caracterizada como vínculo empregatício. Ela propôs uma readequação da noção de subordinação jurídica, argumentando que, na atualidade, ela não se limita à sujeição pessoal do empregado a ordens e comandos do empregador, mas alcança também "situações nas quais o trabalhador se insere na dinâmica da atividade empresarial e cumpre objetivamente suas regras e protocolos” (PGR, 2017, p.16). A essa nova configuração ela designou de subordinação estrutural e afirmou ser o observado comumente em atividades desenvolvidas pelos profissionais dentro dos salões de beleza.

Além disso, a manifestação da PGR indicou que mesmo o pagamento via comissão deve ser considerado pagamento regular de remuneração e os trabalhadores devem seguir padrões de horários de atendimento ao cliente, indo de encontro ao argumento da presença de liberdade de horários, apresentado no projeto de lei. Diante desses e de outros argumentos, a PGR afirmou que a Lei do Salão Parceiro facilitou o mascaramento da relação empregatícia por meio de instrumento formal de contrato de parceria e a declarou inconstitucional (PGR, 2017). Entendemos, então, que a PGR está ratificando as alegações e iniciativa da CONTRATUH.

Dessa forma, a aprovação da Lei do Salão Parceiro se sustentou em discurso que promete liberdade, flexibilidade e modernidade para a realidade do setor de beleza, por meio da passagem dos trabalhadores para a figura de empreendedor. Entretanto, indagamo-nos se sua aplicação tem sustentado o "mito do trabalho autônomo" e se pode implicar perdas 
no bem-estar, saúde e proteção social, além da desestruturação da classe trabalhadora. Ao mesmo tempo que facilita que profissionais informais obtenham formalização, ela também abre espaço para que os empregados, regidos pela CLT, percam garantias trabalhistas e promove a exclusão dos trabalhadores do sistema de garantias dos direitos sociais. Serviria, então, de exemplo para o que autores como Hewison (2013), Kalleberg e Hewison (2013) e Standing (2013/2017) têm caracterizado como formas de precarização.

Posto isso, questionamos se esses trabalhadores do setor de beleza realmente conhecem a Lei do Salão Parceiro e a figura jurídica do MEI, se entendem as implicações e consequências da mudança da condição de empregado ou informal para a situação de “empreendedor", e se a prestação de serviços é de fato autônoma e com liberdade. Por isso, o objetivo do presente estudo foi caracterizar a percepção de manicures e cabeleireiras(os) acerca de suas experiências de trabalho e confrontá-la com os argumentos presentes na proposição da Lei do Salão Parceiro.

\section{Estratégia metodológica}

\section{Participantes}

Participaram do estudo 11 trabalhadoras(es) de salões de beleza de Belo Horizonte, sendo cinco cabeleireiras(os) e seis manicures. O critério para o número de participantes foi de saturação, isto é, até que identificássemos a lógica interna na fala do grupo pesquisado (Minayo, 2014). Do total, apenas dois participantes eram do sexo masculino, sendo ambos cabeleireiros. Em relação aos vínculos de trabalho praticados, três eram empregadas(os), três informais, três MEIs que antes eram informais e dois MEIs que antes eram empregadas(os) (pejotizadas/os). A idade das participantes variou de 18 a 67 anos $(\mathrm{M}=40,54$ anos $)$. O tempo médio de trabalho no setor foi de 17 anos, variando de 4 a 40 anos, e o tempo médio de trabalho no salão de beleza atual foi de 7,3 anos, com variação entre um mês e 27 anos.

\section{Procedimentos de campo e análise das informações}

As entrevistas semiestruturadas foram conduzidas individualmente dentro dos salões de beleza. $\mathrm{O}$ acesso aos salões e às(aos) participantes foi por conveniência. Fizemos contato prévio com salões de beleza via telefone e, naqueles em que obtivemos autorização, aguardamos presencialmente o momento em que profissionais estavam disponíveis e dispostas(os) a participar. As entrevistas duraram em média 20,4 minutos, respeitando a disponibilidade de participação e centrando-se no foco do conteúdo. O roteiro semiestruturado abordou temas de trajetória da trabalhadora, aspectos da atividade, da empresa e trabalhistas e do MEI. As entrevistas eram iniciadas após explicação da pesquisa e assinatura do Termo de Consentimento Livre e Esclarecido (TCLE). Optamos por manicures e cabeleireiras(os) por serem as profissões mais representativas nos salões de beleza. 
Gravamos as entrevistas, as transcrevemos na íntegra e, como caminho para compreensão das respostas, aplicamos a técnica de análise hermenêutica-dialética (Minayo, 2014). Para isso, seguimos as etapas recomendadas por Minayo. Ordenamos o material e realizamos a leitura exaustiva das entrevistas, buscando identificar a lógica interna das informações. Para facilitar esse primeiro momento, utilizamos o software QDA Miner para construir categorias empíricas. Em seguida, realizamos a leitura transversal do conjunto, agrupando as categorias semelhantes de modo a alcançar categorias centrais, as unidades de sentido, em uma lógica unificadora e contextualizada diante do que sabíamos dos salões a partir da literatura revisada e dos documentos consultados.

A análise foi realizada por meio de um movimento circular (em que revíamos o material analisado a cada núcleo de sentido identificado). Começamos por categorias mais fragmentadas e avançamos para núcleos de sentidos mais abrangentes. Consideramos sempre a individualidade de cada entrevistado, sua fala e, ao mesmo tempo, o contex to no qual ele está inserido. Dessa forma, pudemos compreender as entrevistas dos sujeitos como parte dos processos sociais. Optamos por apresentar os resultados da análise em conjunto com sua discussão, de modo a alcançar o objetivo da pesquisa.

\section{Resultados e discussão}

Organizamos o conteúdo da fala das(os) participantes em três unidades de sentido: (a) Caracterização mercadológica e ocupacional, (b) Tradições trabalhistas no setor de beleza e (c) Realidade após a Lei do Salão Parceiro.

\section{Caracterização mercadológica e ocupacional}

A primeira unidade situou-nos na atividade das(os) participantes, abrangendo as noções gerais a respeito da ocupação e do mercado de beleza, sendo elas: tendências no mercado da beleza, aprendizagem informal, dependência das clientes, identificação com a atividade e diferenças de reconhecimento social.

Em relação ao mercado da beleza, as(os) participantes relataram que os produtos e as técnicas estão sempre em evolução, de modo a oferecer aos clientes mais opções, tecnologia e qualidade. As manicures contaram, por exemplo, que hoje em dia o serviço apresenta opções como a esmaltação comum, unhas de gel, de vidro e alongamentos. Marcas brasileiras de produtos para cabelo, pele e unha vêm ganhando destaque, permitindo o barateamento de alguns serviços. Isso aponta um dos efeitos da expansão das indústrias de cosméticos no país. Outro efeito, porém, é o acesso e uso caseiro pelas clientes dos produtos utilizados na execução dos serviços pelas(os) profissionais, causando a ausência dessas mesmas clientes nos salões.

As(os) entrevistadas(os), de maneira geral, relataram queda na remuneração nos últimos anos. Elas(eles) atribuíram as causas ao aumento do número de salões na cidade, com geração de maior concorrência, e à crise econômica vivida pelo país, que fez com que as clientes optassem por executar o serviço em casa, por conta própria. Mencionaram outras causas, como mudanças nas responsabilidades fiscais que cada profissional assumiu após a aprovação da Lei do Salão Parceiro. 
Chamaram-nos atenção os relatos a respeito da crise econômica, uma vez que os índices econômicos apontaram que o mercado de beleza sofreu pouco seus efeitos (ABIHPEC, 2018). Uma possível explicação, mencionada indiretamente pelas(os) entrevistadas(os), é a venda direta à cliente dos produtos produzidos pela indústria, fazendo com que os resultados desse setor puxassem os resultados globais do mercado de beleza. Além disso, fazendo um paralelo com o problema da alta mortalidade dos empreendimentos do setor, indicado no projeto da Lei do Salão Parceiro, esses relatos das(os) entrevistadas(os) apontam novas perspectivas de respostas para sua causa: concorrência, crise econômica e mudança na dinâmica de consumo.

Em relação à formação para a prática profissional, de maneira geral, as(os) participantes disseram ter aprendido na prática como executar os serviços, indo ao encontro de alguns estudos realizados no Brasil (Gallon, Bitencourt, Viana \& Antonello, 2016; Oliveira, 2014). Identificamos também a presença de tradição familiar no relato de algumas entrevistadas(os), tendo o ofício passado de pai/mãe para filha(o). Um ponto comum entre as(os) cabeleireiras(os) foi o curso de formação, que não as(os) impediu de também afirmar que o conhecimento fora adquirido na prática diária, enquanto os cursos de especialização as(os) habilitam a utilizar novas técnicas em surgimento no mercado.

O relacionamento com as clientes, chamadas no sexo feminino pela maioria das(os) participantes, tem lugar de destaque nas entrevistas. Ao mesmo tempo que trabalhar com o embelezamento e a autoestima das pessoas foi descrito como aspecto positivo da atividade, as(os) entrevistadas(os) relataram que o humor da cliente interfere na execução e satisfação, característica comum no setor de serviços (Meirelles, 2006). Além desse aspecto, elas relataram que a fidelidade das clientes à profissional garante o trabalho e remuneração desta, mas também a imobiliza de mudar para outros salões e/ou localidades de trabalho, já que a criação de uma nova clientela é um processo árduo e arriscado. Uma manicure entrevistada, por exemplo, disse que "mudar de uma esquina para outra” já é o suficiente para a cliente não optar mais pelo salão e pelo trabalho dela. Portanto, ainda que ser manicure e cabeleireira(o) seja relatado como um trabalho flexível, que pode ser feito em qualquer lugar, a realidade das(os)entrevistadas(os) é de dependência em relação à clientela já criada e ao próprio salão, que se torna uma referência para que essas clientes cheguem até a profissional. Dessa forma, os relatos contradizem o argumento do projeto de lei de que as clientes são fiéis ao profissional, e não ao salão.

Como pontos de identificação com a atividade, as(os) participantes relataram satisfação pelo resultado final dos serviços e pela felicidade e reconhecimento das clientes. Com exceção das(os) entrevistadas(os) que estão na iminência de se aposentar, a maioria pretende permanecer no setor de beleza, mesmo visualizando que o esforço físico inerente ao trabalho seja um problema a partir de idades mais avançadas. As aspirações envolveram tornar-se proprietária(o) de um salão e, no caso das manicures, exercer também outras atividades como cabeleireira e esteticista. Essa diferença entre manicures e cabeleireiras(os) pode estar relacionada à diferença real de ganho entre as duas profissões, uma vez que os serviços de cabelo costumam ser mais caros e, portanto, o comissionamento da(o) profissional também é maior, ou ainda, à diferença de reconhecimento pela sociedade.

Apesar das(os) participantes terem relatado que o reconhecimento social das profissões melhorou nos últimos anos, as manicures ainda vivenciam preconceito. Essa diferença de reconhecimento é relatada, inclusive, pelas(os) próprias(os) cabeleireiras(os), evidenciando uma hierarquia das profissões interna ao salão. Estudos realizados no Brasil 
(Dweck \& Sabbato, 2006; Oliveira, 2014) e na Colômbia (Arango \& Pineda, 2012) já apontaram para tal diferença entre ser cabeleireira(o) e ser manicure, sendo esta última opção um fazer ainda associado ao trabalho doméstico, de menor conhecimento e retorno financeiro.

\section{Tradição trabalhista no setor de beleza}

Esta unidade de sentido descreve as práticas trabalhistas tradicionais do setor de beleza e abrange as noções de remuneração por comissão, carteira como fachada e ausência de relação com o sindicato. Tradicionalmente, a(o) profissional recebe por comissão sobre o serviço prestado e o custo dos produtos fica sob sua responsabilidade; no caso das(os) cabeleireiras (os), é comum o salão ter estoque dos produtos e o valor daqueles utilizados ser abatido na comissão. A porcentagem da comissão varia entre manicures e cabeleireiras(os), sendo a das manicures, de maneira geral, menor - entre $30 \%$ e $40 \%-$, enquanto a das(os) cabeleireiras(os) entre $50 \%$ e $60 \%$. Dessa forma, a remuneração das manicures permanece menor devido a essa porcentagem e ao valor cobrado pelos serviços de unha, que costumam ser menores que dos serviços de cabelo.

A remuneração por comissão foi um dos fatores relatados como causa da competição entre as(os) profissionais. Entrevistadas relataram histórias de disputa por clientes dentro dos salões, já que a remuneração é dependente da quantidade de serviços prestados. Uma prática que os salões adotam para evitar tais disputas é o direcionamento aleatório, pelos atendentes e telefonistas, dos clientes às profissionais. Mas na prática, conforme as(os) entrevistadas(os), esse direcionamento não demonstra ser tão aleatório, dependendo das preferências da clientela, do tempo de casa da(o)profissional e das relações entre as(os) colegas de trabalho.

Em relação aos vínculos praticados antes da aprovação do Salão Parceiro, as entrevistas apontaram presença de trabalhadoras(es) informais e empregados. Essas(es), porém, independentemente de ainda terem a carteira de trabalho assinada pelo salão, descrevem uma relação de emprego dissimulada. Isso porque o salão assina a carteira constando o valor do piso salarial da categoria, mas na prática a $(\mathrm{o})$ trabalhadora $(\mathrm{o})$ paga todos os encargos que deveriam ser responsabilidade da empresa, recebe por comissão, não tem direito a férias remuneradas e não recebe $13^{\circ}$ salário. Ainda assim, ao questionarmos as(os) entrevistadas(os) a respeito da preferência em relação aos tipos vínculos, a maioria escolheu a relação de emprego com carteira assinada, alegando a segurança que as leis trabalhistas garantem em comparação à situação de informalidade e/ou de empreendedorismo.

Assim como evidenciado no projeto de lei do Salão Parceiro, as(os) entrevistadas(os) verbalizaram a respeito da insegurança jurídica presente nas relações trabalhistas. Entretanto, essa insegurança foi representada pela informalidade e pela situação de dissimulação da situação de emprego. Dessa forma, ao invés de legalizar a situação dessas(es) profissionais por meio da regularização das relações trabalhistas, a lei ofereceu uma alternativa mais fácil para os salões, de modo que eles não precisem assinar a carteira de trabalho das(os) empregadas(os). Portanto, ao mesmo tempo em que o registro como MEI regularizou muitos informais, retirou também direitos daqueles que deveriam ser beneficiados pelos direitos trabalhistas, realidade já prevista nas discussões levantadas pela CONTRATUH (2016) durante a tramitação da lei, pela manifestação da PGR (2017) e por autores, como Fernandes (2018) e Santos (2017). 
Outra noção presente na unidade de sentido a respeito das tradições trabalhistas do setor é a ausência de relação dessas(es) profissionais com o sindicato. Todas(os) as(os) 11 entrevistadas(os) disseram não saber a respeito da atuação da entidade. Os profissionais de beleza são representados em Minas Gerais pela FETHEMG(Federação dos Empregados em Turismo e Hospitalidade do Estado de Minas Gerais) e buscamos saber junto à instituição como ela vem atuando, mas não obtivemos resposta. A mudança dessas(es) profissionais para a figura do MEI provavelmente dificultará mais as(os) profissionais encontrarem interesses comuns, manterem-se unidas(os) e sua representação por uma estrutura sindical tradicional. Essa realidade de desmonte da classe trabalhadora já foi descrita por autores, como Antunes (2018), Galvão e Teixeira (2017), Standing (2013/2017) e Krein (2013).

\section{Realidade após a Lei do Salão Parceiro}

Nas unidades de sentido anteriores, caracterizamos como as entrevistadas(os) percebem o mercado, a ocupação e as práticas trabalhistas antes da Lei do Salão Parceiro. Nesta última serão descritas as noções relacionadas à realidade após a aprovação da lei. Foram elas: desconhecimento da lei e MEI por submissão.

Primeiramente chamou-nos a atenção a falta de informação a respeito da lei. A maior parte das(os) entrevistadas(os) não soube descrevê-la, apesar de saber da sua existência e sentir mudanças após a sua aprovação. Se a falta de informação foi um problema indicado pelo deputado Ricardo Izar (2013) no projeto de lei, as entrevistas indicaram que após a sua aprovação a lei passou a integrar o rol de informações que as(os) profissionais não conhecem.

Apenas um cabeleireiro soube explicar seu conteúdo e aplicação, e afirmou que ela veio para "formalizar o que já acontecia antes", remetendo-se à dissimulação da relação de emprego. Ele contou que na teoria o vínculo seria como empreendedor autônomo, mas que na prática o salão precisa do profissional como um empregado, exigindo uso de uniforme e presença em horários determinados. O mesmo entrevistado ainda acrescentou que a lei protege os salões de beleza dos processos trabalhistas que, de acordo com ele, eram comuns anteriormente. A realidade descrita por esse participante revela, na prática, o que os estudos sobre pejotização (como, Oliveira, 2013; Pereira, 2013) descrevem como evidências do fenômeno.

Isso nos leva à segunda noção presente nesta unidade de sentido: a realidade do MEI por submissão, que se apresentou nas entrevistas de maneira contrária à ideia de autonomia defendida na proposição da Lei do Salão Parceiro. O primeiro aspecto dessa realidade é o processo de transição para a figura do MEI, descrito pelas(os) participantes como tendo sido realizado pelos próprios salões de beleza. Algumas(uns) relataram que a empresa reuniu a equipe para explicar a mudança, mas ainda assim nenhuma(um) entrevistada(o) soube explicar de maneira aprofundada o que é a nova figura jurídica e quais são seus direitos e deveres.

Outro aspecto que caracterizamos como o MEI por submissão foi a própria noção do que seja ser autônoma(o), trazida pelas(os) entrevistadas(os). Seguindo o discurso do "mito do trabalho autônomo" (Antunes, 2018; Jesus, 2016), a fala das(os) participantes exaltou a flexibilidade de horários. Elas(es) alegaram que podem escolher os dias e horários de trabalho e que podem tirar férias quando quiserem. Ao descreverem a realidade, entretanto, elas(es) contaram que os salões de beleza exigem que elas(es) se 
disponibilizem para marcar qualquer horário junto ao cliente e que nunca conseguem tirar férias porque dependem do trabalho para receber a comissão. Isso suporta o que a PGR (2017) apresenta em sua manifestação contra a Lei do Salão Parceiro quando afirma que há um padrão de horários a ser seguido. Além disso, o trabalho também apareceu nas entrevistas como atividade que demanda alta disponibilidade, apropriando-se do tempo das demais esferas de vida (por exemplo, para o lazer). A aparente contradição discursiva das(os) entrevistadas provavelmente decorre da absorção do discurso dominante contido no projeto de lei em tela que não lhes favorece desenvolver a crítica a partir da experiência. Na condição de MEI, certamente não contam com ajuda da organização trabalhista para desenvolver uma reflexão crítica sobre tal contradição.

Esse ponto de vista sobre os horários a serem seguidos pelas(os) trabalhadoras(os) torna o conceito de subordinação estrutural (PGR, 2017) adequado a essa realidade. Ainda que, em alguns casos, as ordens de comando não sejam explícitas, se a(o) trabalhadora(or) não se adequar à dinâmica do salão de beleza, ela(e) não fará parte da equipe. Há, portanto, uma ameaça (mesmo que implícita) disciplinadora.

Outro aspecto acerca da condição de autônoma foi o relato de participantes sobre a queda na remuneração nos últimos anos. Além das causas mercadológicas já mencionadas, houve mudanças nos processos internos dos salões de beleza. Participantes disseram que, a partir da aprovação da lei, cada profissional passou a ser dona(o) de uma máquina de cartão, de modo que os encargos dos pagamentos realizados por meio de cartão de crédito ou débito fossem assumidos por quem executou o serviço, alcançando, na teoria, a distinção das responsabilidades tributárias que o projeto de lei objetivava. As novas responsabilidades fiscais, entretanto, exigiram conhecimentos que as(os) entrevistadas(os) disseram não possuir, evidenciando, mais uma vez, a desinformação acercada nova condição.

Duas entrevistadas levantaram um outro ponto, a respeito do valor da aposentadoria que a condição de MEI oferecerá. Uma vez que a contribuição mensal ao INSS (Instituto Nacional do Seguro Social) segue o padrão do programa, o valor da aposentadoria também seguirá o padrão, independendo da remuneração real do profissional. Dessa forma, quem quiser se planejar para manter a renda próxima à recebida atualmente, precisará complementar o valor do recolhimento ou contribuir adicionalmente a uma previdência privada.

Se considerarmos as(os) profissionais que antes eram informais, elas(es) relataram que a transição para o MEI garantiu acesso a alguns direitos, como a já descrita aposentadoria, licença maternidade e auxílio-doença. Entretanto, as(os) mesmas(os) entrevistadas(os) não demonstraram saber que tais direitos também estariam presentes se contribuíssem com o INSS sem serem, necessariamente, MEIs. Portanto, os direitos exaltados pelas(os) participantes não foram instituídos pela adesão ao MEI e independem da aprovação da Lei do Salão Parceiro. 


\section{Considerações finais}

As unidades de sentido identificadas no presente estudo, e suas respectivas noções, confirmaram a presença de contradições entre os argumentos presentes no projeto de lei do Salão Parceiro e a percepção que manicures e cabeleireiras(os) constroem a partir do que vivenciam na prática de trabalho. Chamou-nos a atenção a homogeneidade presente nas respostas e nas histórias relatadas, indicando que as condições às quais as(os) trabalhadoras(es) estão submetidas(os), independente do vínculo praticado, são muito parecidas. Os elementos de atividade autônoma indicados no projeto de lei não encontraram correspondência a uma autonomia real na experiência das entrevistadas e a desinformação apareceu como um traço forte quando o assunto abordado foi a nova lei e a figura jurídica do MEI.

Dito isso, foi possível identificar que a Lei do Salão Parceiro se insere e reafirma o "mito do trabalho autônomo", dentro de um discurso de "empreendedorismo" que atende aos interesses do sistema econômico capitalista neoliberal em voga, o qual ganha novos contornos para conseguir se manter. Um desses contornos é a transferência de uma série de responsabilidades que antes deveriam ser dos salões de beleza para o trabalhador, que agora assume a figura de empreendedor. Essa transferência também está relacionada ao aumento da incerteza, vulnerabilidade, instabilidade e insegurança da situação de trabalho, evidências que autores apontaram caracterizando o trabalho precarizado (como Kalleberg \& Hewinson, 2013; Hewison, 2016; Standing, 2017).

Desenvolvemos esta pesquisa em moldes exploratórios, entretanto a caracterização desenvolvida aqui da percepção das(os) cabeleireiras(os) e manicures acerca de suas experiências de trabalho poderá, certamente, favorecer a realização de novas pesquisas mais estruturadas e sustentadas em um quadro teórico das relações de trabalho, que focalize fenômenos como a precarização do trabalho, terceirização e formas de exploração do trabalhador sob a condução da economia em conformidade aos princípios do neoliberalismo.

O desenvolvimento do estudo também evidenciou o desafio para o estabelecimento de novas regulações que atendam às particularidades do trabalho no setor de serviços. A reinvenção dessas maneiras de se trabalhar e dos trabalhadores se organizarem politicamente indica caminhos para estudos na área da Psicologia Social e da Psicologia do Trabalho e das Organizações, para que não percamos o olhar sobre o trabalhador.

\section{Notas}

1 Confederações são associações sindicais de grau superior, compostas por mínimo de três federações e têm sede na Capital da República (Decreto_Lei n. 5452/1943). É o órgão máximo de representação do ponto de vista da estrutura sindical no que diz respeito a sua dimensão hierárquica. Enquanto isso, as centrais sindicais são estruturas que reúnem diversas entidades do ponto de vista horizontal.

2 ADI é o instrumento utilizado no controle de constitucionalidade das leis e atos normativos, exercido perante o Supremo Tribunal Federal (Lei n. 9868/1999). 


\section{Referências}

ABIHPEC - Associação Brasileira da Indústria de Higiene Pessoal, Perfumaria e Cosméticos. (2018). Panorama do Setor 2018. Recuperado de https://abihpec.org.br/publicacao/panorama-do-setor-2018/

Alves, G. (2013). Precarização do trabalho e saúde do trabalhador no Brasil. In Dimensões da Reestruturação Produtiva: Ensaios de sociologia do trabalho (pp. 127-140). Bauru/SP: Editora Canal 6.

Antunes, R. (2018). O privilégio da servidão: o novo proletariado de serviços na era digital. São Paulo: Boitempo.

Arango, L. G. \& Pineda, J. A. (2012). Género, trabajo y desigualdades sociales en peluquerías y salones de belleza de Bogotá. Revista CS, 10, 93-130. doi: 10.18046/recs.i10.1356

Arnold, D. \& Bongiovi, J. R. (2013). Precarious, informalizing, and flexible work: transforming concepts and understandings. American Behavioral Scientist, 57(3), 289-308. doi: $10.1177 / 0002764212466239$

Barbosa, A. M. S. \& Orbem, J. B. (2015). "Pejotização": precarização das relações de trabalho, das relações sociais e das relações humanas. Revista Eletrônica do Curso de Direito da UFSM, 10(2), 1-21. doi: 10.5902/1981369420184

Barros, R. P. (2014). A pejotização como uma fraude à relação de emprego: uma análise do fenômeno. In S. G. C. L. Silva (Org.), Transformações no mundo do trabalho e redesenhos institucionais: trabalho, instituições e direitos (pp. 237 - 252). São Paulo: LTr.

Bonciu, F. (2017). Evaluation of the impact of the 4th industrial revolution on the labor market. Romanian Economic and Business Review, 12(2), 7-16.

Bridi, M. A., \& Braunert, M. B. (2015). O trabalho na indústria de software: a flexibilidade como padrão das formas de contratação. Caderno CRH, 28(73), 199-213.

Carvalho, M. A. L. (2010). Pejotização e descaracterização do contrato de emprego: o caso dos médicos em Salvador - Bahia. Dissertação de Mestrado, Programa de Pós-graduação em Políticas Sociais e Cidadania, Universidade Católica do Salvador, Salvador, BA. Recuperado de http://www.desenvolvimentoqs.ufba.br/sites/desenvolvimentoqs.ufba.br/files/MARIA\%20 AMELIA\%20LIRA\%20DE\%20CARVALHO.pdf

CONTRATUH. (2016). Ação direta de inconstitucionalidade $n^{0}$ 5.625. Ação requerida pela Confederação Nacional dos Trabalhadores em Turismo e Hospitalidade ante a Presidencia da República e o Congresso Nacional. Brasília. Recuperado de http://portal.stf.jus.br/processos/ detalhe.asp?incidente $=5094239$

Decreto-lei n. 5.452, de 01 de Maio de 1943. (1943). Aprova a Consolidação das Leis do Trabalho. Diário Oficial da União, Brasília. Recuperado de http://www.planalto.gov.br/ccivil_03/ Decreto-Lei/Del5452.htm

Dweck, R. H. \& Sabbato, A. D. (2006). A beleza e o mercado de trabalho: uma perspectiva de gênero. Revista Gênero, 7(1) 95-128. Recuperado de http://www.revistagenero.uff.br/index. $\mathrm{php} /$ revistagenero/article/viewFile/348/260

Fernandes, P. R. (2018). Breves comentários à Lei do salão parceiro (13.352/2016). Revista Eletrônica do Tribunal Regional do Trabalho da $9^{a}$ Região, 7(66), 27-34. Recuperado de https://juslaboris.tst.jus.br/handle/20.500.12178/129830

Gallon, S., Bitencourt, B. M., Viana, D. D., \& Antonello, C. M. (2016). Formas de aprendizagem e saberes no trabalho de manicures. Revista Pensamento Contemporâneo em Administração, 10(1), 96-112. doi: 10.12712/rpca.v10i1.655 
Galvão, A. \& Teixeira, M. O. (2018). Flexibilização na lei e na prática: o impacto da reforma trabalhista sobre o movimento sindical. In J. Krein, D. M. Gimenez, \& A. Santos, (Orgs.), Dimensões críticas da reforma trabalhista no Brasil (pp. 155-182). Campinas/SP: Curt Nimuendajú.

Hewison, K. (2016). Precarious work. In S. Edgell, H. Gottfried, \& E. Granter (Orgs.), The SAGE handbook of the sociology of work and employment (pp. 428-443). Los Angeles, CA: SAGE Reference.

Izar, R. (2013). Projeto de Lei da Câmara dos Deputados no 5.230, de 26 de março de 2013. Dispõe sobre a regulamentação e base de tributação do "salão-parceiro" e do "profissionalparceiro". Brasília, DF. Recuperado de https://www25.senado.leg.br/web/atividade/materias/-/ $\underline{\text { materia/123222 }}$

Kalleberg, A. L. \& Hewison, K. (2013). Precarious Work and the Challenge for Asia. American Behavioral Scientist, 57(3), p. 271-288. doi: 10.1177/0002764212466238

Krein, J. D. (2013). As transformações no mundo do trabalho e as tendências das relações de trabalho na primeira década do século XXI no Brasil. Revista do Núcleo de Estudo de Economia Catarinense, 2(3), 6-25. Recuperado de http://incubadora.periodicos.ufsc.br/index.php/ $\underline{\text { necat/article/view/2785/3313 }}$

Krein, J. D., Abílio, L., Freitas, P., Bolsari, P., \& Cruz, R. (2018). Flexibilização das relações de trabalho: insegurança para os trabalhadores. In J. Krein, D. M. Gimenez, \& A. Santos (Orgs.), Dimensões críticas da reforma trabalhista no Brasil (pp. 95-122). Campinas, SP: Curt Nimuendajú.

Jesus, N. C. (2016). Informalidade e empreendedorismo: uma configuração da precariedade do trabalho "empreendedor" na rua 25 de março/SP. Estudos do Trabalho, 18/19, 153-183.

Lei n. 9.868, de 10 de novembro de 1999. (1999). Dispõe sobre o processo e julgamento da ação direta de inconstitucionalidade e da ação declaratória de constitucionalidade perante o Supremo Tribunal Federal. Diário Oficial da União, Brasília. Recuperado de http://www.planalto. gov.br/ccivil 03/LEIS/L9868.htm

Lei n. 11196, de 21 de Novembro de 2005. (2005). Institui o Regime Especial de Tributação para a Plataforma de Exportação de Serviços de Tecnologia da Informação - REPES, o Regime Especial de Aquisição de Bens de Capital para Empresas Exportadoras - RECAP e o Programa de Inclusão Digital; dispõe sobre incentivos fiscais para a inovação tecnológica. Diário Oficial da União, Brasília. Recuperado de http://www.planalto.gov.br/ccivil 03/_Ato2004-2006/2005/ Lei/L11196.htm

Lei Complementar n. 128, de 19 de dezembro de 2008. (2008). Cria a figura do microempreendedor individual - MEI e modifica partes da Lei Geral da Micro e Pequena Empresa - Lei Complementar 123/2006. Diário Oficial da União, Brasília. Recuperado de http://www.planalto.gov.br/ccivil_03/leis/LCP/Lcp128.htmf

Lei n. 12.592, de 18 de janeiro de 2012. (2012). Dispõe sobre o exercício das atividades profissionais de Cabeleireiro, Barbeiro, Esteticista, Manicure, Pedicure, Depilador e Maquiador. Diário Oficial da União, Brasília. Recuperado de http://www.planalto.gov.br/ccivil 03/ ato2011-2014/2012/lei/112592.htm

Lei n. 13.352, de 27 de outubro de 2016. (2016). Altera a Lei no 12.592, de 18 de janeiro 2012, para dispor sobre o contrato de parceria entre os profissionais que exercem as atividades de Cabeleireiro, Barbeiro, Esteticista, Manicure, Pedicure, Depilador e Maquiador e pessoas jurídicas registradas como salão de beleza. Diário Oficial da União, Brasília. Recuperado de http:/www.planalto.gov.br/ccivil 03/ ato2015-2018/2016/lei/L13352.htm

Meirelles, D. S. (2006). O conceito de serviço. Revista de Economia Politica, 26(1), 119-136. Minayo, M. C. S. (2014). O desafio do conhecimento. Pesquisa qualitativa em saúde. São Paulo: Hucitec. 
Oliveira, J. A. (2014). Fazendo a vida fazendo a unha: uma análise sociológica do trabalho de manicure. Tese de Doutorado, Programa de Pós-graduação em Sociologia, Universidade de São Paulo, São Paulo. Recuperado de http://www.teses.usp.br/teses/disponiveis/8/8132/tde05032015-104355/en.php

Oliveira, L. M. (2013). Pejotização e a precarização das relações de emprego. Revista Atitude - Construindo Oportunidades,7(14), 25-31.

Pereira, L. (2013). Pejotizacao: o trabalhador como pessoa jurídica. São Paulo: Saraiva.

Procuradoria Geral da República - PGR. (2017). Manifestação da PGR na ação direta de inconstitucionalidade $\mathrm{n}^{\mathrm{o}}$ 5.625. Ação requerida pela Confederação Nacional dos Trabalhadores em Turismo e Hospitalidade ante a Presidência da República e o Congresso Nacional. Brasília. Recuperado de http://portal.stf.jus.br/processos/downloadPeca.asp?id=312747036\&ext=.pdf Santos, A. D. (2017). Pejotização e fraude nas relações de emprego: análise dos efeitos trabalhistas e fiscais-tributários (o caso dos salões de beleza). Revista Âmbito Jurídico, 162, 1-26.

Schwab, K. (2016). A quarta revolução industrial (D. M. Miranda, trad.). São Paulo: Edipro. SEBRAE - Serviço Brasileiro de Apoio às Micro e Pequenas Empresas. (2017). Panorama dos Pequenos Negócios 2017. Recuperado de https://m.sebrae.com.br/Sebrae/Portal\%20 Sebrae/UFs/SP/Pesquisas/Panorama\%20dos\%20Pequenos\%20Negocios\%202017.pdf

Silva, C. M. (2014). A precarização da atividade jornalística e o avanço da pejotização. Dissertação de Mestrado, Programa de Pós-graduação em Comunicação, Universidade de Brasília, Brasília, DF. Recuperado de http://repositorio.unb.br/handle/10482/15710

Standing, G. (2017). O precariado: a nova classe perigosa. (C. Antunes, Trad). Belo Horizonte: Autêntica.

Thébaud-Mony, A. \& Druck, G. (2007). Terceirização: a erosão dos direitos dos trabalhadores na França e no Brasil. In G. Druck, \& T. Franco (Orgs.), A perda da razão social do trabalho: terceirização e precarização (pp. 23-58). São Paulo: Boitempo.

Venâncio, D. M., Dutra, A., Fiates, G. G. S., \& Feuerschütte, S. G. (2015). Comprometimento organizacional: confrontando o comprometimento afetivo e instrumental entre trabalhadores autônomos e efetivos de salões de beleza. Holos, 31(2), 169-182. doi: 10.15628/holos.2015.1525 


\section{MARIANA MACHADO SOUZA}

https://orcid.org/0000-0001-8901-174X

Mestra em Psicologia pela Universidade Federal de Minas Gerais.

Endereço: UFMG, Faculdade de Filosofia e Ciências Humanas, Av. Antônio

Carlos, 6627, Bairro Pampulha, CEP: 31270-910. Belo Horizonte/MG.

E-mail: mmachadosouza@gmail.com

\section{LIVIA DE OLIVEIRA BORGES}

\section{https://orcid.org/0000-0003-2251-1373}

Psicóloga e Mestre em Administração de Recursos Humanos (UFRN).

Doutora em Psicologia (UnB) com estágio pós-doutoral na Universidade

Complutense de Madri. Professora da UFMG, no Programa de Pósgraduação em Psicologia.

Bolsista de Produtividade em Pesquisa pelo CNPq.

E-mail: liviadeoliveira@gmail.com

\begin{tabular}{|l|l|}
\hline \multirow{3}{*}{ Histórico } & $\begin{array}{l}\text { Submissão: 20/01/2019 } \\
\text { Revisão: 21/03/2020 } \\
\text { Aceite: 20/04/2020 }\end{array}$ \\
\hline \multirow{3}{*}{ Contribuição dos autores } & $\begin{array}{l}\text { Concepção: MMS; LOB } \\
\text { Coleta de dadlos: MMS; LOB } \\
\text { Análise de dados: MMS; LOB } \\
\text { Elaboração do manuscrito: MMS; LOB } \\
\text { Aprovação final do manuscrito: MMS; LOB }\end{array}$ \\
\hline Consentimento de uso de imagem & Não se aplica \\
\hline Aprovação, ética e consentimento & $\begin{array}{l}\text { O estudo foi aprovado pelo Comitê de Ética em Pesquisa da } \\
\text { Universidade Federal de Minas Gerais }\end{array}$ \\
\hline Financiamento & Bolsa de Mestrado - CNPQ \\
\hline
\end{tabular}

